\title{
Characterization of the Flavin-Protein Interaction in L-Lactate Oxidase and Old Yellow Enzyme by Resonance Inverse Raman Spectroscopy
}

Rachelle J. Bienstock $\nmid \ddagger$, Lawrence M. Schopfer $\S$ and Michael D. Morris*†

Departments of Chemistry and Biological Chemistry, University of Michigan, Ann Arbor, Michigan 48109, USA

\begin{abstract}
Resonance inverse Raman spectroscopy was used to examine the interactions between the flavin and surounding protein in L-lactate oxidase (from Mycobacterium smegmatis) and Old Yellow Enzyme (from brewer's bottom yeast). Spectra were taken of the enzymes both free and bound to various ligands. For L-lactate oxidase, the ligands consisted of substrate analogs (acetate, propionate) and inorganic anions (phosphate, sulfate and nitrate). For the inorganic anions, the expected attenuation with detuning was not observed for several bands which are associated with flavin rings II and III. This effect appears to be due to a disruption of ring stacking between the uracil-pyrazine end of the flavin moiety and an aromatic amino acid. A shift in the $1232 \mathrm{~cm}^{-1}$ band and changes in the bandwidths of bands in the $1450-1600 \mathrm{~cm}^{-1}$ region indicate minor reorganization of the hydrogen bonding structure around the isoalloxazine on ligand binding.

For Old Yellow Enzyme, the ligand was chloride. Chloride caused a slight change to the Raman spectrum, indicative of decreased hydrogen bonding to the flavin.
\end{abstract}

\section{INTRODUCTION}

Raman spectroscopy has been used extensively in the past 8 years for studies on free flavins ${ }^{1-3}$ and flavoproteins. ${ }^{1,5-7}$ Vibrational assignments have been made for many of the bands in the flavin spectrum 8,9 and a normal mode analysis has been described. ${ }^{10,11}$ Since Raman spectroscopy gives a detailed picture of vibronic structure, it provides a sensitive probe of the immediate environment of the flavin. This is of particular interest in flavoproteins, where the flavin environment is selectively orchestrated by the protein. In addition, the flavin-protein environment is subject to change as the protein binds substrates or inhibitors. We have employed Raman spectroscopy to examine L-lactate oxidase (E.C. 1.13.12.4) from Mycobacterium smegmatis (AATC 14468) and Old Yellow Enzyme (E.C. 1.6.99.1) from brewer's bottom yeast in both the free and the ligand-bound states.

L-Lactate oxidase is an FMN-containing enzyme which catalyzes the oxidation of L-lactic acid to acetic acid and carbon dioxide. It is normally studied in a $10 \mathrm{~mm}$ imidazole- $\mathrm{HCl}$ buffer in order to minimize exposure to anions. ${ }^{12}$ Anions such as phosphate, sulfate and nitrate and a variety of short-chain aliphatic acids bind to L-lactate oxidase, inhibit the enzyme reaction and cause significant perturbations in the absorption spectrum of the flavin. ${ }^{12,13}$ The short-chain aliphatic substrate analogs acetate and propionate and the inorganic anions bind to L-lactate oxidase, causing minor shifts in the positions of the Raman bands and significant

\footnotetext{
* Author to whom correspondence should be addressed.

$\dagger$ Department of Chemistry.

$\doteqdot$ Present address: Texas Instruments Central Research Labora tories, Material Science Laboratory, P.O. Box 225936, Dallas, Texas 75265, USA.

$\S$ Department of Biological Chemistry.
}

changes in band intensities. These intensity changes are indicative of ring stacking interactions between the flavin and an aromatic amino acid residue.

Old Yellow Enzyme is also an FMN-containing flavoenzyme. It is reduced by NADPH, but its physiological oxidant is uncertain. ${ }^{14,15}$ Anions such as chloride, azide and acetate and a variety of phenolates bind to Old Yellow Enzyme and inhibit the reductive half of the reaction. ${ }^{15,16}$ The Raman spectrum of free enzyme was found to have an extremely close correspondence to the flavin components of complex spectra involving Old Yellow Enzyme and various phenolates. ${ }^{17,18}$ These earlier spectra were given as confirmatory evidence for the charge-transfer nature of Old Yellow Enzymephenolate complexes, as proposed by Abramovitz and Massey, ${ }^{19}$ a point to which objection has recently been raised. ${ }^{20}$ Our results support the charge-transfer assignment. The monovalent anion $\left(\mathrm{Cl}^{-}\right)$caused small shifts in the flavin's Raman bands at 1295 and $1480 \mathrm{~cm}^{-1}$ and the appearence of new bands at 1192 and $1315 \mathrm{~cm}^{-1}$. The changes were generally suggestive of a decrease in hydrogen bonding to the flavin.

\section{EXPERIMENTAL}

We have used inverse Raman spectroscopy, a coherent Raman technique, to obtain spectra of enzymes and their complexes. The experimental apparatus was similar to earlier designs ${ }^{21,22}$ except that the nitrogen-pumped dye laser was replaced with an excimer-pumped system. The $514.5 \mathrm{~nm}\left(19436 \mathrm{~cm}^{-1}\right)$ argon ion line was used as the pump beam. Raman frequencies were calculated from the observed non-Lorentzian bands by comparison of experimental with theoretical curves. ${ }^{23-25}$ The $S_{0}^{0}$ values used in these experiments were measured from the second derivatives of the absorption spectra, ${ }^{26}$ as 
described by Massey et al. ${ }^{27}$ The half-width at halfmaximum on the low-energy side of the band was taken as the effective damping constant, $\Gamma_{e}$, for band shape calculations.

Potassium nitrate $(0.1 \mathrm{M}$, aqueous) was used as an external intensity and frequency standard. The inverse Raman spectrum of a nitrate standard was measured before and after acquisition of each enzyme spectrum. All spectral intensities were normalized to the nitrate $1052 \mathrm{~cm}^{-1}$ band and then corrected for the attenuation of the pump (argon ion beam) by dividing the observed signals by their fractional transmittance. The argon ion laser beam was attenuated $\left(0.4-0.1 \mathrm{~A} \mathrm{~cm}^{-1}\right)$ by the enzyme sample. Typically, intensities were reproducible to $\pm 10 \%$. The dye laser wavelength range, $545-563 \mathrm{~nm}$, lay, well to the red of the absorption spectrum of the flavin. Careful alignment of the laser beams minimized thermal lens artifacts resulting from the small $\left(<0.001 \mathrm{~A} \mathrm{~cm}^{-1}\right)$ sample absorbance in this region.

L-Lactate oxidase was prepared as described by Sullivan et $a l^{28}$ and Old Yellow Enzyme as described by Abramovitz and Massey. ${ }^{19}$ Sample preparation is described in the figure legends.

\section{RESULTS AND DISCUSSION}

\section{L-Lactate oxidase}

The Raman spectra of $0.27 \mathrm{~mm}$ L-lactate oxidase under various conditions are shown in Fig. 1. Trace A shows lactate oxidase in $10 \mathrm{~mm}$ imidazole- $\mathrm{HCl}(\mathrm{pH} \mathrm{7.0})$. The spectrum is essentially identical with that obtained by Visser et $\mathrm{al}^{4}{ }^{4}$ and is characterized by strong bands at $1180,1232,1264,1366,1418,1596$ and $1633 \mathrm{~cm}^{-1}$. Weaker bands are found at 1142 and $1200 \mathrm{~cm}^{-1}$ and in the $1450-1560 \mathrm{~cm}^{-1}$ region.

The $1232 \mathrm{~cm}^{-1}$ band (band XI) was shifted to higher wavenumbers in the presence of acetate $\left(5 \mathrm{~cm}^{-1}\right)$, propionate $\left(10 \mathrm{~cm}^{-1}\right)$, phosphate $\left(5 \mathrm{~cm}^{-1}\right)$ and water $\left(5 \mathrm{~cm}^{-1}\right)$. Sulfate and piperazine- $N, N^{\prime}$-bis (2-ethanesulfonic acid) (PIPES) caused no shift. Nitrate broadened the band, making an exact frequency assignment difficult. In addition, bands II and III were split in nitrate solution.

Band shifts in the $1200-1300 \mathrm{~cm}^{-1}$ region have been previously assigned to changes in the vibrational structure around $\mathrm{N}-3$ (see structure $\mathrm{I}$ ), associated with hydrogen bonding $5,7,9,29$ or deuteriation ${ }^{29}$ at $\mathrm{N}-3-\mathrm{H}$. An increase in the frequency is generally interpreted as increasingly strong hydrogen bonding at this position. Thus, $\mathrm{N}-3-\mathrm{H}$ hydrogen bonding to the protein matrix is strengthened by binding propionate, acetate or phosphate to L-lactate oxidase.

$$
\left.\overbrace{6}\right|_{6} ^{2}
$$

In the $1450-1600 \mathrm{~cm}^{-1}$ region, resolved or broadened bands appear under certain experimental conditions. Changes of this nature are typically associated with
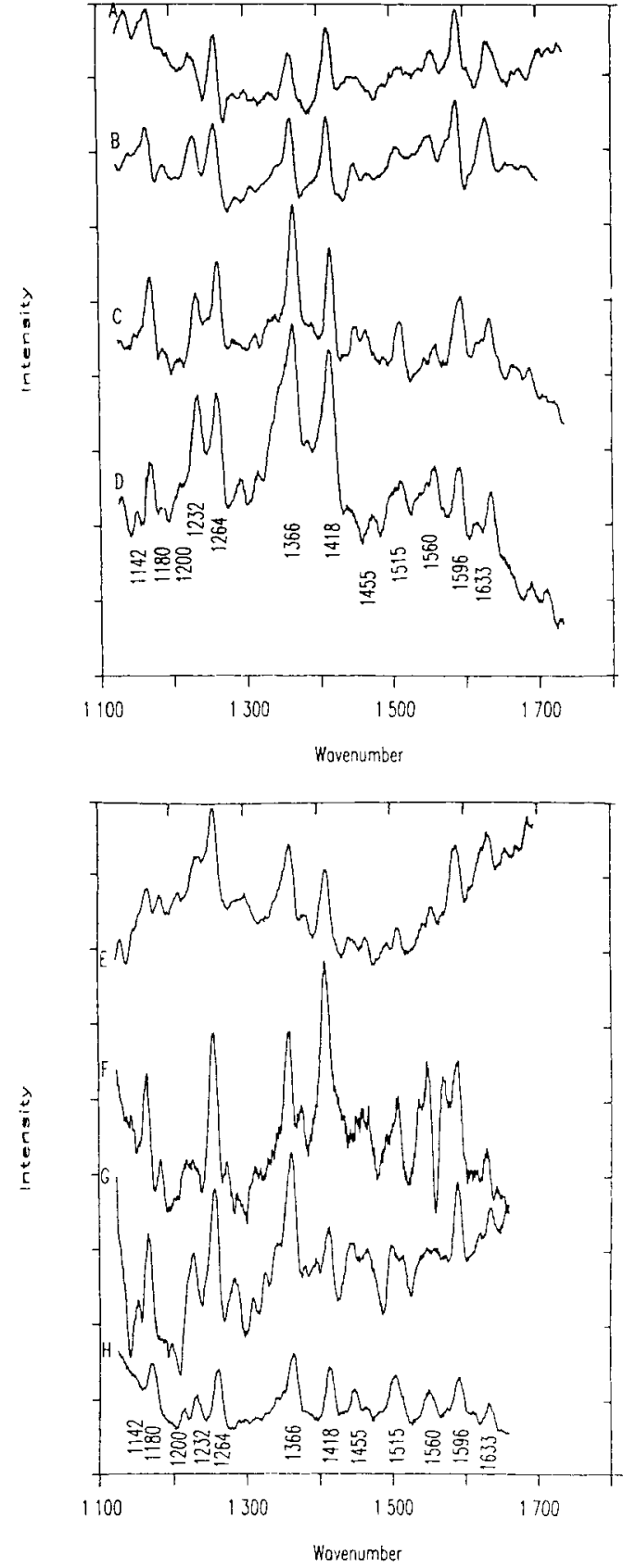

Figure 1. Resonance inverse Raman spectra of L-lactate oxidase $(0.27 \mathrm{~mm})$ taken in (A) $10 \mathrm{~mm}$ imidazole-HCl buffer $(\mathrm{pH} \mathrm{7.0)}$, (B) $10 \mathrm{~mm}$ PIPES buffer $(\mathrm{pH} 7.0)$. (C) no buffer $(\mathrm{pH} 7.0)$, (D) $10 \mathrm{~mm}$ imidazole- $\mathrm{HCl}$ buffer ( $\mathrm{pH} 7.0$ ) plus $0.21 \mathrm{M}$ sodium acetate, (E) $10 \mathrm{~mm}$ imidazole- $\mathrm{HCl}$ buffer $(\mathrm{pH} 7.0)$ plus $60 \mathrm{~mm}$ sodium propionate, ( $\mathrm{F}$ ) $10 \mathrm{mM}$ imidazole-HCl buffer ( $\mathrm{pH} 7.0)$ plus $20 \mathrm{~mm}$ sodium nitrate, $(\mathrm{G})$ $10 \mathrm{~mm}$ imidazole- $\mathrm{HCl}$ buffer $(\mathrm{pH} 7.0)$ plus $0.2 \mathrm{M}$ sodium sulfate, $(\mathrm{H})$ $0.2 \mathrm{M}$ potassium phosphate buffer $(\mathrm{pH} 7.0)$. Ligand concentrations were all 10 times or more higher than their respective dissociation constants for L-lactate oxidase, except for chloride, which was used at $20 \%$ of its dissociation value to minimize complications with the imidazole buffer. Dissociation constants: phosphate, $12 \mathrm{~mm}$; nitrate $0.4 \mathrm{~mm}$; sulfate, $13 \mathrm{~mm}$; and chloride, $50 \mathrm{~mm}^{12}$ acetate, $11 \mathrm{~mm}^{13}$ and propionate, $\leqslant 1.6 \mathrm{~mm}$ (Schopfer and Massey, unpublished results). Temperature, ambient. Each spectrum was normalized to an external nitrate standard $(0.1 \mathrm{M})$. Laser excitation frequency, $514.5 \mathrm{~nm}$.

changes in the hydrogen bonding structure of the chromophore. ${ }^{30}$ In this instance, however, we cannot assign hydrogen bonding effects to a specific locus on the flavin. It should be noted in this context that the C-2 
Table 1. Relative intensity measurements of the flavin Raman bands for L-lactate oxidase, free and in complex ${ }^{\mathrm{R}}$

\begin{tabular}{|c|c|c|c|c|c|c|c|c|c|}
\hline \multirow[b]{2}{*}{ Band" } & \multirow[b]{2}{*}{$\mathrm{cm}^{-1}$} & \multicolumn{7}{|c|}{ Intensityc } & \multirow[b]{2}{*}{$\mathrm{SO}_{4}^{2-}$} \\
\hline & & Imidazole & PIPES & Water & Propionate & Acetate & $\mathrm{PO}_{4}^{2-}$ & $\mathrm{NO}_{3}^{-}$ & \\
\hline 1 & 1633 & 4.08 & 4.53 & 3.93 & 2.90 & 2.37 & 0.94 & 1.29 & 1.41 \\
\hline II & 1596 & 8.36 & 7.84 & 3.93 & 4.20 & 2.72 & 1.27 & 2.93 & 4.59 \\
\hline III & 1560 & 2.41 & 1.99 & 1.22 & 1.30 & 1.80 & 0.94 & 3.86 & 0.71 \\
\hline IV & 1515 & 1.31 & 1.09 & 3.81 & 0.72 & 1.23 & 1.81 & 2.01 & 3.88 \\
\hline V & 1455 & 2.50 & 1.49 & 2.04 & 1.45 & 0.71 & 0.78 & 1.74 & 3.39 \\
\hline VI & 1418 & 6.39 & 7.25 & 6.71 & 6.52 & 6.25 & 1.57 & 4.59 & 4.23 \\
\hline VII & 1366 & 6.26 & 7.25 & 7.50 & 6.29 & 6.18 & 1.97 & 3.04 & 6.89 \\
\hline$x$ & 1264 & 9.20 & 7.84 & 5.61 & 7.60 & 4.31 & 1.81 & 3.67 & 7.41 \\
\hline$X I$ & 1232 & 5.08 & 3.26 & 4.63 & 4.84 & 3.45 & 0.63 & 0.73 & 2.82 \\
\hline XII & 1200 & 1.71 & 1.18 & 1.61 & 1.30 & 0.57 & 0.24 & 1.18 & 1.76 \\
\hline XIII & 1180 & 4.20 & 4.62 & 4.55 & 1.88 & 2.01 & 1.34 & 2.84 & 5.83 \\
\hline \multirow{3}{*}{\multicolumn{2}{|c|}{$\begin{array}{l}S_{0}^{0}\left(\mathrm{~cm}^{-1}\right)^{d} \\
\Gamma_{e} \\
\left(\omega_{0}-\omega_{1}\right) / \Gamma_{e}\end{array}$}} & 20492 & 20492 & 20492 & 20534 & 20661 & 20704 & 20790 & 20790 \\
\hline & & 698 & 656 & 698 & 611 & 661 & 624 & 588 & 667 \\
\hline & & 1.5 & 1.6 & 1.9 & 1.8 & 1.9 & 2.0 & 2.3 & 2.0 \\
\hline
\end{tabular}

and C-4 carbonyl stretching vibrations are not seen in the Raman spectrum of flavin. ${ }^{31}$ Hydrogen bonding at these points would be indirectly expressed by its influence on adjacent Raman-active modes. We conclude that perturbations to the flavin/protein hydrogen bonds are small. The effects caused by the addition of anions to L-lactate oxidase are less than the differences between the flavin environments in different enzymes.

The origin of the first flavin electronic transition shifts toward the blue as anions are added to the system. The substrate analogs shift the orgin by $50-150 \mathrm{~cm}^{-1}$ and the inorganic inhibitors cause larger shifts of $200-300 \mathrm{~cm}^{-1}$. The constraints of our experiment preclude acquisition of complete excitation profiles. However, we can compare intensities at fixed pump (argon ion) frequency (Table 1).
Table 2 shows the intensities of the flavin Raman bands, relative to their values in imidazole buffer. The band intensities in PIPES are about the same as those in imidazole. The expected decrease, due to detuning, is observed in some bands in the presence of substrate analogs acetate and propionate. However, several bands remain at or near their imidazole intensities, although the pump beam position is about 1.9 damping constants below the orgin of the transition. A similar behavior is observed with the inorganic anion inhibitors. In the presence of these ions, the expected intensity decrease is not observed for all bands and some bands are even more intense than in imidazole or PIPES alone.

In unbuffered solution, band IV is unusually intense. We include data in unbuffered solution for completeness. However, absence of electrolyte is known to

Table 2. Relative intensity measurements of the flavin Raman bands for L-lactate oxidase, free and in complex normalized to the imidazole values

\begin{tabular}{|c|c|c|c|c|c|c|c|c|c|}
\hline \multirow[b]{2}{*}{ Band ${ }^{b}$} & \multirow[b]{2}{*}{$\mathrm{cm}^{-1}$} & \multicolumn{7}{|c|}{ Intensity ${ }^{C}$} & \multirow[b]{2}{*}{$\mathrm{SO}_{4}^{2}$} \\
\hline & & Imidazole & PIPES & Water & Propionate & Acetate & $\mathrm{PO}_{4}^{2-}$ & $\mathrm{NO}_{3}^{-}$ & \\
\hline 1 & 1633 & 1.00 & 1.11 & 0.96 & 0.71 & 0.58 & 0.23 & 0.32 & 0.35 \\
\hline II & 1596 & 1.00 & 0.94 & 0.47 & 0.50 & 0.33 & 0.15 & 0.35 & 0.55 \\
\hline III & 1560 & 1.00 & 0.83 & 0.51 & 0.54 & 0.75 & 0.39 & 1.60 & 0.29 \\
\hline IV & 1515 & 1.00 & 0.83 & 2.90 & 0.55 & 0.94 & 1.38 & 1.53 & 2.95 \\
\hline V & 1455 & 1.00 & 0.60 & 0.82 & 0.58 & 0.28 & 0.31 & 0.70 & 1.36 \\
\hline VI & 1418 & 1.00 & 1.13 & 1.05 & 1.02 & 0.98 & 0.25 & 0.72 & 0.66 \\
\hline VII & 1366 & 1.00 & 1.16 & 1.20 & 1.00 & 0.99 & 0.31 & 0.49 & 1.10 \\
\hline$x$ & 1264 & 1.00 & 0.85 & 0.61 & 0.83 & 0.47 & 0.20 & 0.40 & 0.81 \\
\hline$X 1$ & 1232 & 1.00 & 0.64 & 0.91 & 0.95 & 0.68 & 0.12 & 0.14 & 0.56 \\
\hline$X I I$ & 1200 & 1.00 & 0.69 & 0.94 & 0.76 & 0.33 & 0.14 & 0.69 & 1.03 \\
\hline XIII & 1180 & 1.00 & 1.10 & 1.08 & 0.45 & 0.48 & 0.32 & 0.68 & 1.39 \\
\hline \multicolumn{2}{|c|}{$S_{0}^{0}\left(\mathrm{~cm}^{-1}\right)^{d}$} & 20492 & 20492 & 20492 & 20534 & 20661 & 20704 & 20790 & 20790 \\
\hline \multicolumn{2}{|c|}{$\Gamma_{\mathrm{o}}$} & 698 & 656 & 698 & 611 & 661 & 624 & 558 & 667 \\
\hline \multicolumn{2}{|c|}{$\left(\omega_{0}-\omega_{1}\right) / \Gamma_{e}$} & 1.5 & 1.6 & 1.9 & 1.8 & 1.9 & 2.0 & 2.3 & 2.0 \\
\hline
\end{tabular}


perturb protein tertiary structure. Unbuffered solutions may not show Raman behavior consistent with systems at physiological ionic strength.

We interpret the unusual retention of band intensity in the presence of anions as removal of Raman hypochromism present in the imidazole- and PIPES-buffered enzymes, that is, in the buffers bands III-VI and XIIXIII are attenuated by ring stacking. All of the affected bands are composed largely of uracil and/or pyrazine motions, implying the normal presence of an aromatic ring over the uracil/pyrazine end of the molecule. In the presence of anions, this stacking is disrupted.

To determine whether the aromatic ring was imidazole from the buffer or an aromatic amino acid chain from the protein, we examined L-lactate oxidase buffered in $10 \mathrm{~mm}$ PIPES (pH 7.0) (Fig. 1, trace B) or unbuffered in water $\mathrm{pH} 7$ (trace $\mathrm{C}$ ), conditions where aromatic ring stacking from the solvent was precluded. These traces show that, under these conditions, the Raman spectra were essentially the same as that obtained in imidazole buffer. Hence the ring stacking must derive from the protein and represent a normal component of the flavin binding site in L-lactate oxidase. Ring stacking, similar to that proposed here, is seen in the crystal structure of Desulfovibrio vulgaris flavodoxin. It involves tryptophan, tyrosine and flavin. ${ }^{32}$

Nitrate and sulfate complexes of L-lactate oxidase (Fig. 1, traces $F$ and $G$ ) resulted in Raman spectra which were very similar to that of the phosphate complex. A significant enhancement in the bands at $1180,1455,1515$ and $1560 \mathrm{~cm}^{-1}$ occurred in each case (Table 2), although the enhancement factor for each band varied with the anion.

\section{Old yellow enzyme}

The Raman spectrum of Old Yellow Enzyme (0.26 mm) in $50 \mathrm{mM} \mathrm{KP_{ \textrm {i } }}$ buffer ( $\mathrm{pH} 7.0$ ) is shown in Fig. 2, trace A. This spectrum is typical of a flavoprotein, with strong bands at 1239, 1265, 1362, 1412, 1509, 1589 and $1631 \mathrm{~cm}^{-1}$ and weaker bands at $1128,1170,1295,1451$, 1480 and $1547 \mathrm{~cm}^{-1}$. Band VII, at $1362 \mathrm{~cm}^{-1}$, appears to have a shoulder on the low wavenumber side. This

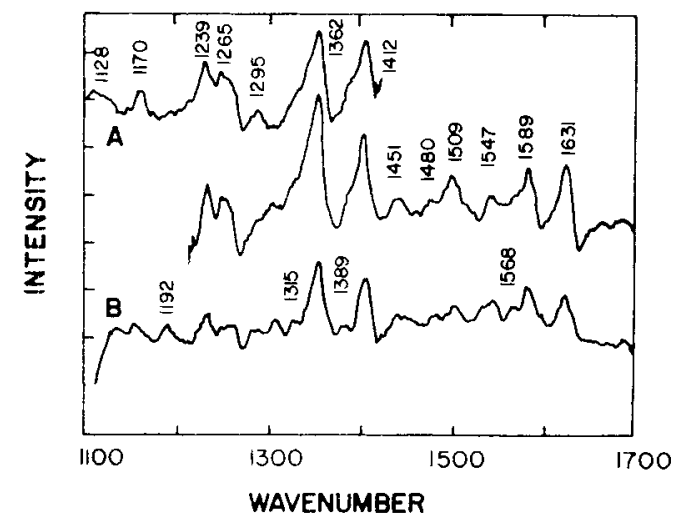

Figure 2. Resonance inverse Raman spectra of Old Yellow Enzyme $(0.26 \mathrm{~mm}$ ) taken in (A) $50 \mathrm{~mm}$ potassium phosphate buffer (pH 7.0); (B) buffer plus $0.2 \mathrm{M}$ potassium chloride Dissociation constant for $\mathrm{Cl}^{-}, 10 \mathrm{~mm}$; phosphate does not bind. ${ }^{15}$ Temperature, ambient. Each spectrum was normalized to an external nitrate standard $(0.1 \mathrm{M})$. Laser excitation frequency, $514.5 \mathrm{~nm}$.

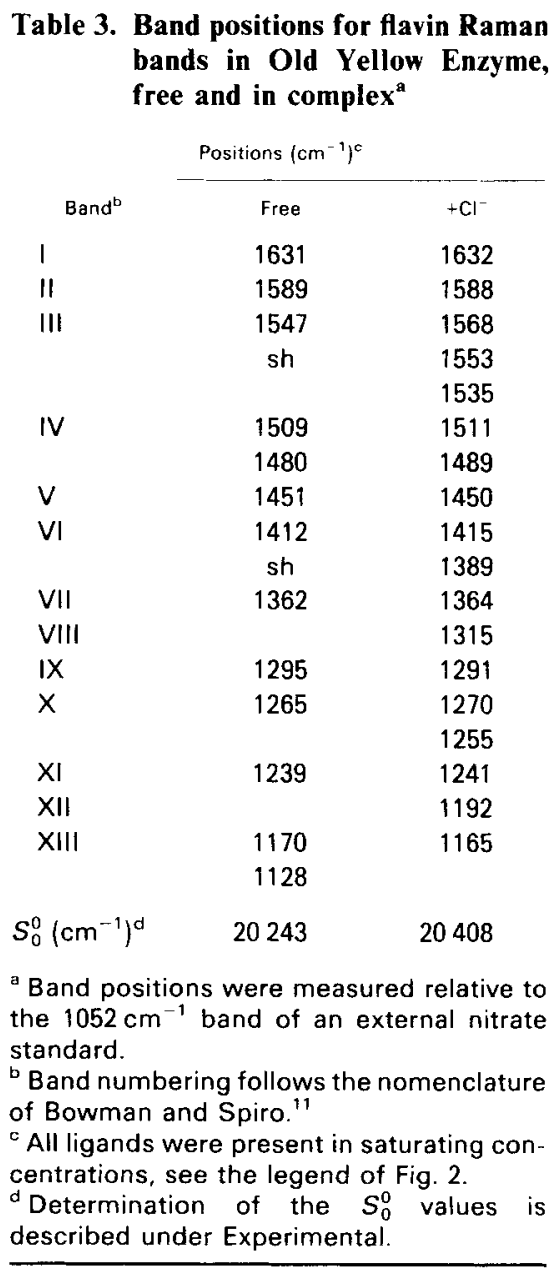

band is normally found to be broad and has been reported as a doublet for several flavoproteins. ${ }^{4,25,33} \mathrm{~A}$ distinct shoulder is also found on the low wavelength side of bands VI $\left(1412 \mathrm{~cm}^{-1}\right)$ and II $\left(1589 \mathrm{~cm}^{-1}\right)$. Addition of saturating concentrations of chloride to Old Yellow Enzyme caused marked changes to the absorbance spectrum but caused only minor changes to the Raman spectrum (Fig. 2). Comparing trace $A$ (unliganded) and trace $\mathrm{B}$ (in the presence of $\mathrm{Cl}^{-}$), using the corrected band positions in Table 3 , it can be seen that the majority of the bands in trace $A$ have a counterpart in trace $B$, to within $2 \mathrm{~cm}^{-1}$. Only the weak bands at 1295 and $1480 \mathrm{~cm}^{-1}$ are shifted $\left(5-10 \mathrm{~cm}^{-1}\right)$. Shoulders on the bands at 1412 and $1589 \mathrm{~cm}^{-1}$ are resolved, appearing at 1389 and $1568 \mathrm{~cm}^{-1}$, respectively. The broad bands at 1265 and $1547 \mathrm{~cm}^{-1}$ appear to be resolved into two bands each in the complex. In addition, two new bands appear in the complexed spectrum, one at $1192 \mathrm{~cm}^{-1}$ and the other at $1315 \mathrm{~cm}^{-1}$.

The protein's response to chloride binding does not seem to alter the immediate environment of the flavin significantly. There is little evidence of significant changes in the hydrogen bond structure around the flavin.

We attempted to measure the Raman spectra of the Old Yellow Enzyme-phenolate complexes without success. The increase in absorbance at our excitation wavelength $(514.5 \mathrm{~nm})$ due to the formation of the complexes appeared to be enough to reduce our signal to 
below the noise level. Our results with the free enzyme, however, do confirm the conclusions from the earlier work of Kitagawa and co-workers ${ }^{9,18}$ on the phenolate complexes of Old Yellow Enzyme. As described above, we have found that ligand binding to Old Yellow Enzyme causes minimal perturbation to most of the Raman bands, while causing the appearance of new bands near 1310 and $1192 \mathrm{~cm}^{-1}$. Comparing the positions of bands attributed to flavin in the phenolate complexes of Nishina $e t$ al ${ }^{18}$ with the band positions in our spectrum of unliganded Old Yellow Enzyme, seven bands were found to correspond to within $3 \mathrm{~cm}^{-1}$ : (theirs vs ours) 1628 vs 1631,1588 vs 1589,1548 vs 1547,1411 vs 1412,1359 vs 1362,1265 vs 1265 and 1240 vs 1239 . In addition, bands at 1310 and $1194 \mathrm{~cm}^{-1}$ were found in their phenolate complexed spectra, and were attributed to the flavin. Thus, we support the conclusion of Nishina et al. that the Raman spectrum of the flavin appeared in their spectra. Their resonance-enhanced Raman spectra were obtained using the longest wavelength absorbance band of the phenolate complex. The spectra contained bands characteristic of phenolate in addition to flavin. Thus, it is reasonable to describe the long-wavelength absorbance bands of these complexes as charge-transfer bands. It is also reasonable to describe the phenolate-Old Yellow Enzyme complexes as charge-transfer complexes, in which the phenolate is the donor and the flavin is the acceptor. This conclusion was arrived at by Kitagawa et $a .^{17}$ from resonance Raman data, confirming an earlier assignment by Abramovitz and Massey. ${ }^{19}$ In view of these data, and the correlation of the energy of the long-wavelength band with the redox potential of the enzyme-bound flavin, ${ }^{34}$ the arguments of Eweg et al. ${ }^{20}$ that the longwavelength absorbance bands in the phenolate-Old Yellow Enzyme complexes are not due to charge-transfer interactions between flavin and phenolate must be disputed.

\section{CONCLUSION}

The Raman spectrum of the flavin in Old Yellow Enzyme is typical of a flavoprotein. There is no evidence to suggest the presence of another chromophore. Binding of $\mathrm{Cl}^{-}$to Old Yellow Enzyme causes only minor perturbations in the Raman spectrum.

In L-lactate oxidase, we have found that binding of phosphate, sulfate, nitrate, acetate or propionate anions causes intensity changes in the Raman spectra of the complexes consistent with the relaxation of a ring stacking interaction between the isoalloxazine ring and an aromatic amino acid side-chain from the protein. Small shifts in the band positions indicate some reorganization of the hydrogen bond structure around the isoalloxazine on ligand binding.

The observations described above indicate that only minor perturbations occur in the Raman spectra of $\mathrm{L}$ lactate oxidase and Old Yellow Enzyme on binding simple ligands. As the size of the ligand and its potential for interacting with the protein increase, the extent of the Raman spectral perturbation also increases. This situation is more dramatically illustrated in the Raman spectra of $p$-hydroxy-benzoate hydroxylase and its ligand complexes. ${ }^{25}$

\section{Acknowledgements}

Acknowledgement is made to the National Science Foundation (CHE8317861) and the United States Public Health Service (GM-11106) for supporting this research.

\section{REFERENCES}

1. P. K. Dutta, J. Nestor and T. G. Spiro, Proc. Natl. Acad. Sci. U.S.A. 74, 4146 (1977)

2. P. K. Dutta, R. Spencer, C. Walsh and T. G. Spiro, Biochim. Biophys. Acta 623, 77 (1980).

3. L. M. Schopfer, J. P. Haushalter, M. Smith, M. Milad and M. D. Morris, Biochemistry 20,6734 (1981).

4. A. J. W. G. Visser, J. Vervoort, D. O’Kane, J. Lee and L. A. Carriera, Eur. J. Biochem. 31, 639 (1983).

5. F. Müller, J. Vervoort, M. Horovitz, J. Lee and L. A. Carreira, J Raman Spectrosc. 14, 106 (1983)

6. M. Benecky, T. Y. Li, J. Schmidt, F. Frerman, K. L. Watters and J. McFarland, Biochemistry 18, 3471 (1979).

7. J. Schmidt, P. Coudron, A. W. Thompson, K. L. Watters and J. McFarland, Biochemistry 22, 76 (1983).

8. Y. Nishina, T. Kitagawa, K. Shiga, K. Horlike, Y. Matsumura, H. Watari and T. Yamano, J. Biochem. (Tokyo) 84, 925 (1978).

9. T. Kitagawa, Y. Nishina, Y. Kyogoku, T. Yamano, N. Ohishi, A. Takai-Suzuki and K. Yagi, Biochemistry 18, 1804 (1979).

10. M. Abe and Y. Kyogoky, in Symposium on Raman Spectroscopy and Biological Science, edited by $T$. Kitagawa and $Y$. Kyogoky, p. 42, abstract D3. Osaka University, Osaka, Japan (1984).

11. W. D. Bowman and T. G. Spiro, Biochemistry 20, 3313 (1981)

12. O. Lockridge, V. Massey and P. A. Sullivan, J. Biol. Chem. 247 8097 (1972).

13. S. Ghisla and V. Massey, J. Biol. Chem. 250, 577 (1975).

14. A. Akeson, A. Ehrenberg and H. Theorell, The Enzymes, 2nd ed Vol. 7, pp. 477-494. Academic Press, New York (1963).

15. V. Massey and L. M. Schopfer, J. Biol. Chem. 261, 1215 (1986).

16. W. J. Rutter and B. Rolander, Acta Chem. Scand. 11, 1663 (1957).

17. T. Kitagawa, Y. Nishina, K. Shiga, H. Watari and T. Yamano, J. Am. Chem. Soc. 101, 3376 (1979).
18. Y. Nishina, T. Kitagawa, K. Shiga, H. Watari and T. Yamano, J. Biochem. (Toyko) 87, 831 (1980).

19. A. S. Abramovitz and V. Massey, J. Biol. Chem. 251, 5321 (1976).

20. J. K. Eweg, F. Müller and W. J. H. van Berkel, Eur. J. Biochem. 129, 303 (1982)

21. J. P. Haushalter, G. P. Ritz, D. J. Wallan and M. D. Morris, Appl. Spectrosc. 34, 144 (1980).

22. C. Buffett and M. D. Morris, Appl. Spectrosc. 35, 203 (1981).

23. J. P. Haushalter and M. D. Morris, Anal. Chem. 53, 21 (1981).

24. R. J. Bienstock and M. D. Morris, in Nonlinear Raman Spectroscopy and Its Chemical Applications, edited by W. Kiefer and D. A. Long, pp. 543-559 Reidel, Dordrecht (1982).

25. R. J. Bienstock, L. M. Schopfer and M. D. Morris, J. Am. Chem. Soc. 108, 1833 (1986).

26. W. L. Butler, Methods in Enzymol. 24, 3 (1972).

27. V. Massey, L. M. Schopfer and W. R. Dunham, in Flavins and Flavoproteins, edited by R. C. Bray, P. C. Engel and S. G. Mayhew, pp. 191-210. Walter de Gruyter, Berlin (1984).

28. P. A. Sullivan, Y. S. Choong, W. J. Schreurs, J. F. Cutfield, J. F. and M. G. Shepherd, Biochem. J. 165, 375 (1977).

29. P. K. Dutta, J. Nestor and T. G. Spiro, Biochem. Biophys. Res. Commun. 83, 209 (1978).

30. D. N. Batchelder and D. Bloor, in Advances in Infrared and Raman Spectroscopy, edited by R. E. Hester and R. J. H. Clark, Vol. 11, p. 139. Wiley, New York (1984)

31. Y. Nishimura, M. Tsuboi, Science 210, 1358 (1980).

32. K. D. Watenpaugh, L. C. Sukir, and L. H. Jensen, Proc. Natl. Acad. Sci. U.S.A. 70, 3857 (1973)

33. G. Williamson, P. C. Engel, Y. Nishina and K. Shiga, FEBS Lett. 138, 29 (1982)

34. R. C. Stewart and V. Massey, J. Biol. Chem. 260, 13639 (1985) 